\title{
Comparative efficacy of two daily use mouthrinses: randomized clinical trial using an experimental gingivitis model
}

\section{Christine Ann Charles ${ }^{(a)}$ James Anthony McGuire ${ }^{(b)}$ Naresh Chandra Sharma(c) James Qaqish(c)}

(a) Johnson \& Johnson Consumer \& Personal Healthcare Products Worldwide, Division of Johnson \& Johnson Consumer Companies, Scientific and Professional Affairs, Research and Development, Morris Plains, NJ, United States of America.

(b) Johnson \& Johnson Consumer \& Personal Healthcare Products Worldwide, Division of Johnson \& Johnson Consumer Companies, Biometric and Clinical Data Systems, Morris Plains, NJ, United States of America.

(c) BioSci Research Canada, Ltd., Mississauga, ON, Canada.

Declaration of Interests: The authors certify that they have no commercial or associative interest that represents a conflict of interest in connection with the manuscript.

Corresponding author:

Christine Ann Charles

E-mail: ccharles@its.jni.com

Received for publication on Apr 19, 2011 Accepted for publication on Jun 22, 2011

\begin{abstract}
Two antimicrobial agents, a fixed combination of essential oils (EOs) and $0.07 \%$ cetylpyridinium chloride (CPC) are found in commercially available mouthrinses, Listerine ${ }^{\circledR}$ Antiseptic and Crest ${ }^{\circledR}$ Pro Health ${ }^{\mathrm{TM}}$, respectively. Both mouthrinses have been shown to control dental plaque and gingivitis in short and longer term studies. The aim of this study was to determine the comparative effectiveness of these two mouthrinses using a 2-week experimental gingivitis model. Qualified subjects were randomly assigned to one of three mouthrinse groups: a fixed combination of EOs, $0.07 \%$ CPC, or negative control (C) rinse. Following baseline clinical assessments and a dental prophylaxis, subjects began a two-week period in which they rinsed twice daily with their assigned rinse and abstained from any mechanical oral hygiene procedures or other oral care products. Subjects were reassessed at the end of the two-week period. One hundred and forty-seven subjects were randomized and 142 completed this study. After two weeks use, the EOs rinse was superior $(p \leq 0.011)$ to the CPC rinse in inhibiting the development of gingivitis, plaque, and bleeding, with $9.4 \%$ and $6.6 \%$ reductions compared to $\mathrm{CPC}$ for gingivitis and plaque, respectively. Both rinses were superior to the negative control rinse $(\mathrm{p}<0.001)$. This study demonstrates that the essential oil-containing mouthrinse has superior antiplaque/antigingivitis effectiveness compared to the $0.07 \%$ $\mathrm{CPC}$-containing mouthrinse without mechanical oral hygiene influence.
\end{abstract}

Descriptors: oils; cetylpyridinium; mouthwashes; dental plaque; gingivitis.

\section{Introduction}

Therapeutic antimicrobial mouthrinses have been shown to be valuable adjuncts to mechanical oral hygiene procedures for the control of supragingival plaque and gingivitis. ${ }^{1}$ A mouthrinse containing a fixed combination of essential oils (Listerine ${ }^{\circledR}$ Antiseptic, Morris Plains, USA) has been shown in a number of six-month clinical trials ${ }^{2-8}$ to have significant antiplaque and antigingivitis efficacy. Efficacy has been acknowledged through ADA acceptance ${ }^{9}$ and a Category I recommendation, i.e., safe and effective, by a U.S. FDA advisory panel reviewing antiplaque products for the control of gingivitis. ${ }^{10}$

The experimental gingivitis mode ${ }^{11}$ in which antiplaque/antigingivitis agents are tested in the absence of mechanical oral hygiene procedures has been used to demonstrate efficacy of the fixed combination of es- 
sential oils ${ }^{12-14}$ and to demonstrate superiority to $0.05 \%$ CPC rinses. ${ }^{15}$ This experimental gingivitis model is useful as a short-term model to determine efficacy of mouthrinse formulations and has been found to be consistent with six-month clinical trials results. The objective of this randomized clinical trial was to determine the comparative antiplaque/ antigingivitis effectiveness of an EOs and a $0.07 \%$ CPC mouthrinse formulation (Crest ${ }^{\circledR}$ Pro Health ${ }^{\mathrm{TM}}$, Procter \& Gamble, Cincinnati, USA) using an experimental gingivitis model.

\section{Methodology}

This was a randomized, controlled, examinerblind, parallel-group clinical trial using the twoweek experimental gingivitis model (Figure 1). This study was conducted in accordance with International Conference on Harmonization Good Clinical practice guidelines. ${ }^{16}$ This international standard for pharmaceutical clinical trials insures credible and accurate data and results management. Subjects aged 18 to 65, who met the following inclusion criteria were included in the study:
- a minimum of 20 sound, natural teeth;

- a mean Modified Gingival Index ${ }^{17} \geq 1.95$, and

- a mean Plaque Index ${ }^{18} \geq 1.95$.

Teeth that were grossly carious, fully crowned or extensively restored, orthodontically banded, abutments, or third molars were not included in the tooth count. Exclusion criteria included:

- a history of significant adverse events with use of oral hygiene products;

- significant oral soft tissue pathology, excluding gingivitis;

- moderate to advanced periodontitis;

- any condition requiring antibiotic prophylaxis prior to an invasive dental procedure;

- antibiotic, anti-inflammatory, or anticoagulant drug therapy during the month prior to the baseline examination;

- participation in a dental clinical trial within the previous 30 days; and

- regular use of chemotherapeutic antiplaque/antigingivitis products within the two weeks prior to the baseline examination.

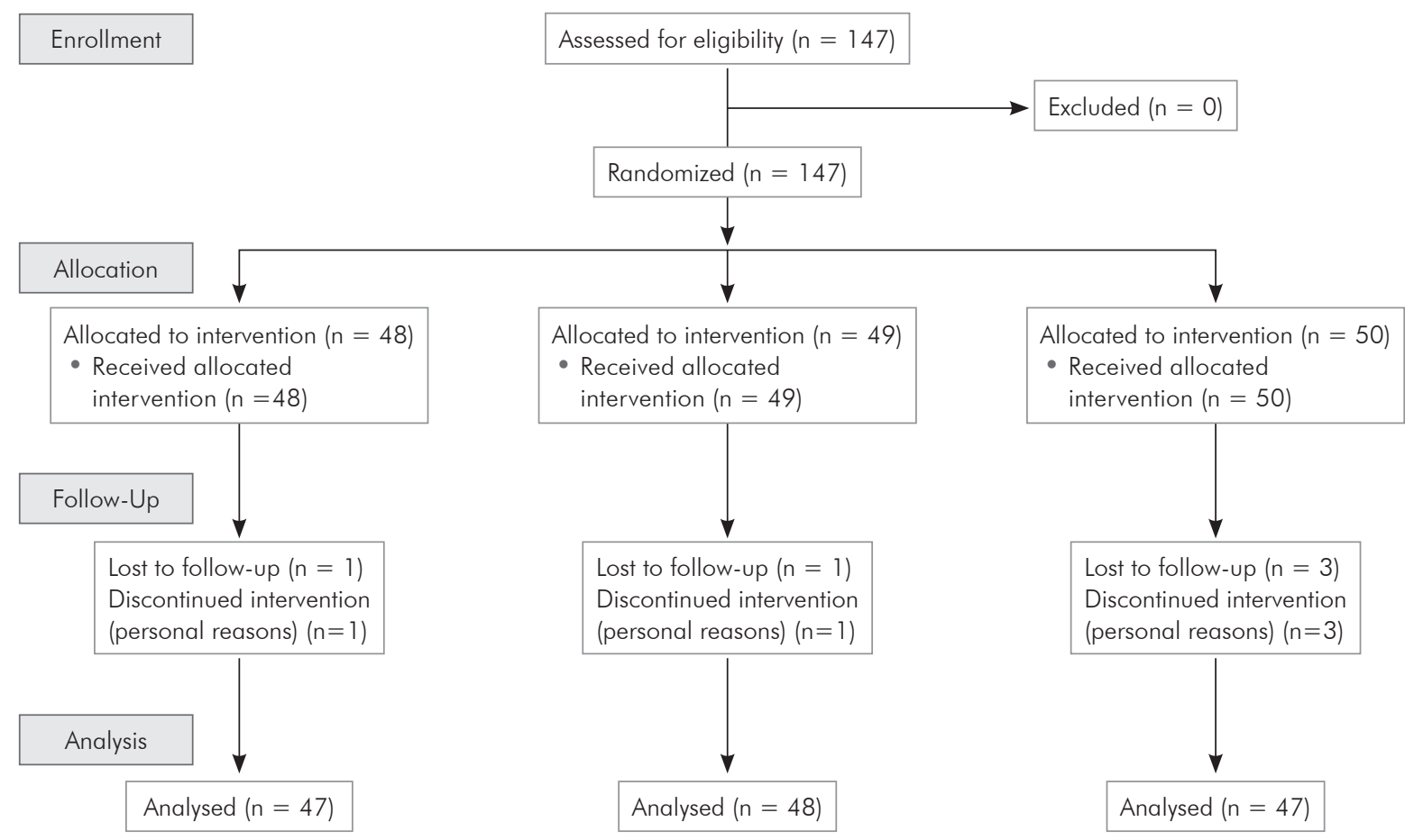

Figure 1 - Study Flow Diagram. Left: control; center: EO; right: CPC. 
All subjects signed an informed consent form after the nature of the study was fully explained to them. The protocol was reviewed by the Institutional BCRL Review Board, Mississauga, Canada.

Prescreened subjects presented to the clinical site for baseline examinations having refrained from any oral hygiene procedures for at least 8 but not more than 18 hours. The baseline examinations consisted of a complete intraoral examination, assessment of gingivitis using the Modified Gingival Index ${ }^{17}$ followed by sulcular bleeding, ${ }^{18}$ and Plaque Index using the Turesky modification of the Quigley-Hein Plaque Index. ${ }^{19}$

Following the baseline examination, qualifying subjects received a complete dental prophylaxis to remove all stain, plaque, and calculus. They were then randomly assigned to one of three groups:

- a group using the essential oil-containing mouthrinse (LISTERINE ${ }^{\circledR}$ Antiseptic, Johnson \& Johnson Consumer \& Personal Products Worldwide, Division of Johnson \& Johnson Consumer Companies Inc., Morris Plains, USA);

- a $0.07 \%$ CPC-containing mouthrinse $\left(\right.$ Crest $^{\circledR}$ Pro-Health $^{\text {TM }}$ Procter \& Gamble, Cincinnati, USA); or

- a negative control group using a $5 \%$ hydroalcohol rinse.

Qualified subjects were assigned product sequentially, in ascending numerical order, according to a block randomization with a fixed block size of 6 . The randomization scheme was generated by a validated SAS-based randomization application developed by the sponsor. Neither the clinical examiner nor the recorder had access to the treatment code. Personnel dispensing study mouthrinses or supervising their use did not have access to the treatment identification and were not involved in examination of the subjects, in order to minimize potential bias.

All mouthrinses were used with the same dosing regimen, i.e., subjects rinsed with $20 \mathrm{ml}$ for $30 \mathrm{sec}$ twice daily. All the rinses were dispensed in overwrapped marketed bottles that were individually labeled with the number of the subject to whom that bottle had been assigned according to the randomization scheme.
Twice-daily rinsing was started immediately following the prophylaxis. The two daily rinses on weekdays were supervised and separated by at least four hours. Subjects were given an individually coded bottle of mouthrinse and plastic dosage cups for unsupervised use on weekends and were provided a diary in which to document unsupervised rinse times. At the end of each weekend period, subjects returned their mouthrinse bottles to the study site and compliance was estimated by measuring the volume of mouthrinse remaining. During the study period, subjects were instructed to discontinue all oral hygiene procedures, other than use of their assigned mouthrinse, and to follow their usual dietary habits.

Subjects used their assigned rinse for 14 days and returned to the clinical site for an oral soft and hard tissue examination and scoring of gingival, bleeding and plaque indices, at least 4 hours after the last use of the test products. All of the examinations and scoring were performed by a single trained and calibrated examiner (N.S.) who did not know to which group the subjects had been assigned and did not have access to the case report forms until all the examinations had been completed.

The repeatability of the examiner for gingival and plaque index scoring was determined prior to the start of the study. The examiner participated in an exercise in which subjects representing the entire scale of the gingival and plaque indices were scored and then rescored in random order after a period of time to avoid the possible recall of scores. The examiner's repeatability of mean index scores was assessed using the intraclass correlation coefficient. The intraclass coefficients for the mean Modified Gingival Index and mean Plaque Index were > 0.9.

\section{Statistical methods}

The primary outcome variables were gingivitis, (Modified Gingival Index) ${ }^{17}$ and supragingival plaque (Turesky modification of the Quigley-Hein Plaque Index). ${ }^{18}$ The secondary outcome variable was gingival bleeding, (Gingival Bleeding Index). ${ }^{19}$ At baseline, the three treatment groups were compared with respect to age, mean Modified Gingival Index, mean Plaque Index, and mean Gingival Bleeding Index by means of a one-way analysis of 
variance model with treatment as a factor, with respect to gender and smoking status by means of a chi-square test, and with respect to race by means of Fishers Exact test.

A sample size of 135 (45 per treatment group) completed subjects was calculated to provide power of 0.90 for detecting a difference of $10 \%$ and $5 \%$ between treatment groups in mean plaque and gingival index scores, respectively. For each of the outcome variables, between-group differences after two weeks of treatment were tested by means of a one-way analysis of covariance model with treatment as a factor and the corresponding baseline value as a covariate. Comparisons were made between the essential oil and negative control rinse, between the CPC and negative control rinse, and between the $\mathrm{EO}$ and $\mathrm{CPC}$ mouthrinses. All tests were performed at the 0.05 level and two-sided. The essential oil-containing mouthrinse was to be considered better than Crest Pro-Health $^{\mathrm{TM}}$ if the essential oil-containing mouthrinse was statistically significantly better than both the $5 \%$ hydroalcohol control and Crest Pro-Health ${ }^{\mathrm{TM}}$ mouthrinses. Each comparison was performed at the 0.05 level of significance, two-sided.

\section{Results}

One hundred forty-seven subjects were randomized into the study to compensate for drop outs, so that 135 subjects could be expected to complete the study. One hundred forty-two subjects completed the study and constituted the intent-to-treat subject population. The baseline demographic characteristics and gingival, plaque, and bleeding indices are shown in Table 1 . There were no statistically sig-

Table 1 - Baseline demographics and clinical means.*

\begin{tabular}{|c|c|c|c|}
\hline Variable & Negative Control $(\mathrm{N}=47)$ & $\mathrm{EO}(\mathrm{N}=48)$ & $\mathrm{CPC}(\mathrm{N}=47)$ \\
\hline \multicolumn{4}{|l|}{ Age (years) } \\
\hline - Mean (SD) & $38.7(10.38)$ & $38.6(9.30)$ & $39.8(9.23)$ \\
\hline - Median & 40 & 40 & 39 \\
\hline - Range & $18-64$ & $18-57$ & $18-60$ \\
\hline \multicolumn{4}{|l|}{ Gender (\%) } \\
\hline - Male & $11(23.4)$ & $12(25.0)$ & $10(21.3)$ \\
\hline - Female & $36(76.6)$ & $36(75.0)$ & $37(78.7)$ \\
\hline \multicolumn{4}{|l|}{ Race (\%) } \\
\hline - White & $35(74.5)$ & $28(58.3)$ & $34(72.3)$ \\
\hline - Black & $3 \quad(6.4)$ & $7(14.6)$ & $4 \quad(8.5)$ \\
\hline - Hispanic & $2 \quad(4.3)$ & $12.1)$ & 0 \\
\hline - Asian/PI & $5(10.6)$ & $7(14.6)$ & $5(10.6)$ \\
\hline - $\mathrm{Al} / \mathrm{AN}^{* *}$ & 0 & $1 \quad(2.1)$ & 0 \\
\hline - Other & $2 \quad(4.3)$ & $4 \quad(8.3)$ & $4 \quad(8.5)$ \\
\hline \multicolumn{4}{|l|}{ Smoker (\%) } \\
\hline - Yes & $11(23.4)$ & $10(20.8)$ & $11(23.4)$ \\
\hline - No & $36(76.6)$ & $38(79.2)$ & $36(76.6)$ \\
\hline \multicolumn{4}{|l|}{ Gingival Index } \\
\hline - Mean (SD) & $2.08(0.057)$ & $2.09(0.060)$ & $2.07(0.048)$ \\
\hline \multicolumn{4}{|l|}{ Plaque Index } \\
\hline - Mean (SD) & $2.96(0.246)$ & $2.91(0.222)$ & $2.96(0.251)$ \\
\hline \multicolumn{4}{|l|}{ - Bleeding Index } \\
\hline - Mean (SD) & $0.17(0.058)$ & $0.19(0.074)$ & $0.17(0.068)$ \\
\hline
\end{tabular}

*For all subjects who had two-week efficacy data; ${ }^{* *}$ American Indian/Alaskan Native. 
Table 2 - Modified Gingival Index Scores, Baseline and Two Weeks.

\begin{tabular}{c|c|c|c|c}
\hline Group & Baseline* & 2-weeks** & $\begin{array}{c}\text { \% Reduction vs. } \\
\text { Negative Control }\end{array}$ & \% Reduction vs. CPC \\
\hline $\begin{array}{c}\text { Negative Control } \\
(n=47)\end{array}$ & $2.08(0.057)$ & $2.09(0.015)$ & - & - \\
\hline $\begin{array}{c}\text { EOs } \\
(n=48)\end{array}$ & $2.09(0.060)$ & $1.74(0.015)^{+a}$ & 16.8 & 9.4 \\
\hline $\begin{array}{c}\text { CPC } \\
(n=47)\end{array}$ & $2.07(0.048)$ & $1.92(0.015)^{\dagger}$ & 8.3 & - \\
\hline
\end{tabular}

*Mean (S.D.); **Adjusted mean (S.E.); †Significantly different from negative control, $\mathrm{p}<0.001$; ${ }^{a}$ Significantly different from CPC, $\mathrm{p}<0.001$.

Table 3 - Plaque Index Scores, Baseline and Two Weeks.

\begin{tabular}{c|c|c|c|c}
\hline Group & Baseline* & 2-weeks* & $\begin{array}{c}\text { \% Reduction vs. } \\
\text { Negative Control }\end{array}$ & \% Reduction vs. CPC \\
\hline $\begin{array}{c}\text { Negative Control } \\
(n=47)\end{array}$ & $2.96(0.246)$ & $3.28(0.044)$ & - & - \\
\hline $\begin{array}{c}\text { EOs } \\
(n=48)\end{array}$ & $2.91(0.222)$ & $2.24(0.043)^{+a}$ & 31.6 & 6.6 \\
\hline $\begin{array}{c}\text { CPC } \\
(n=47)\end{array}$ & $2.96(0.251)$ & $2.40(0.044)$ & 26.7 & - \\
\hline
\end{tabular}

${ }^{*}$ Mean (S.D.); **Adjusted mean (S.E.); ${ }^{\dagger}$ Significantly different from negative control, $p<0.001$; ${ }^{\text {SSignificantly }}$ different from CPC, $\mathrm{p}=0.011$.

nificant differences among the three groups with respect to gender, race, smoking status, or mean gingival, plaque, or bleeding indices. The majority of the subjects were female $(76.8 \%)$, white $(68.3 \%)$ and non-smokers $(77.5 \%)$. The mean age was 39 years (18-64 range) with no statistically significant differences among the three groups.

\section{Primary outcome variables}

The mean values at baseline and two-weeks for the Modified Gingival Index and Plaque Index are presented in Tables 2 and 3, respectively. The comparison of interest, that between the EOs and CPC mouthrinse, demonstrated superiority for the EOs rinse for both gingivitis and plaque, with $9.4 \%$ and $6.6 \%$ reductions versus $\mathrm{CPC}$, respectively. Compared to the negative control at two-weeks, the essential oils (EOs) mouthrinse group had 16.8\% and $31.6 \%$ reductions, respectively, in Modified Gingival Index and Plaque Index $(\mathrm{p}<0.001)$; while the CPC mouthrinse had reductions of $8.3 \%$ and $26.7 \%$, respectively. All treatment differences were statistically significant.
Table 4 - Bleeding Index Scores, Baseline and Two Weeks.

\begin{tabular}{c|c|c}
\hline Group & Baseline* $^{*}$ & 2-weeks** \\
\hline $\begin{array}{c}\text { Negative Control } \\
(\mathrm{n}=47)\end{array}$ & $0.17(0.058)$ & $0.21(0.006)^{\dagger}$ \\
\hline $\begin{array}{c}\text { EOs } \\
(\mathrm{n}=48)\end{array}$ & $0.19(0.074)$ & $0.05(0.006)^{+a}$ \\
\hline $\begin{array}{c}\text { CPC } \\
(\mathrm{n}=47)\end{array}$ & $0.17(0.068)$ & $0.07(0.006)$ \\
\hline
\end{tabular}

${ }^{*}$ Mean (S.D.); ${ }^{* *}$ Adjusted mean (S.E.); † Significantly different from negative control, $p<0.001$; ${ }^{a}$ Significantly different from CPC, $p=0.003$.

\section{Secondary outcome variable}

The mean values at baseline and two-weeks for the Bleeding Index are presented in Table 4. At two weeks, EOs mouthrinse was superior to the CPC mouthrinse and both produced statistically significant differences $(p=0.003)$ compared to the negative control.

\section{Safety evaluations}

No mucosal lesions developed during the course of the study. There were no product-related adverse events. 


\section{Compliance with treatment regimen}

All completed subjects complied with the supervised rinse schedule. Subject diaries and residual mouthrinse quantities at the completion of the two week period indicated compliance with weekend rinsing schedule as well.

\section{Discussion}

Previously this EOs mouthrinse has been shown to have antiplaque and antigingivitis efficacy superior to that of $0.05 \%$ CPC rinses in this same mode ${ }^{15}$ as well as in longer-term studies incorporating mechanical oral hygiene. ${ }^{20,21}$ This study was conducted to determine the comparative efficacy to a higher level $(0.07 \%)$ CPC rinse. This model has demonstrated the clinical superiority of the EOs mouthrinse in reducing supragingival plaque and gingivitis, compared to that of the $0.07 \%$ CPC rinse in the absence of mechanical oral hygiene. In a 3-month randomized clinical trial, EOs + floss + manual brush and paste was shown to be superior to $0.07 \%$ $\mathrm{CPC}+$ floss + manual brush and paste. ${ }^{22}$ In 6 -month trials, ${ }^{23-24}$ this $0.07 \%$ CPC rinse has shown efficacy, however, only the EOs rinse has met the clinical criteria, in 6-month randomized clinical trials, to qualify for ADA acceptance for products indicated for plaque and gingivitis. ${ }^{25}$

This fixed combination EOs mouthrinse containing $0.064 \%$ thymol, $0.092 \%$ eucalyptol, $0.060 \%$ methyl salicylate, and $0.042 \%$ menthol has been previously shown to be an effective antiplaque/antigingivitis product in numerous six-month clinical trials..$^{2-8,20-21}$ The experimental gingivitis model used for this study, in which subjects abstain from all mechanical oral hygiene procedures for the two-week study period, ${ }^{11}$ provides a rigorous test for antiplaque/antigingivitis products and enables a determination to be made of relative chemotherapeutic effectiveness against the dental plaque biofilm in situ.

There are several commercially available mouth-

\section{References}

1. Barnett ML. The role of therapeutic antimicrobial mouthrinses in clinical practice. Control of supragingival plaque and gingivitis. J Am Dent Assoc. 2003 Jun;134(6):699-704. washes with different features and profiles of clinical indication. Some of them are superior to others and thus can provide better results. ${ }^{26}$ The use of effective mouthrinses on a daily basis is proven through scientific data and is indicated to achieve or maintain a healthier mouth leading to a better overall systemic health. ${ }^{20}$ EOs containing mouthwashes present a better $^{26}$ and deeper ${ }^{27}$ bacterial reduction in laboratory biofilm models when compared with several other mouthwashes indicated for daily use and therefore provides support for the clinical superiority in controlling the plaque biofilm. Furthermore, while the cationic properties of CPC help maintain its relatively high substantivity, CPC can interact with negatively charged particles found in other mouthrinses, dentifrices, serum, tissue fluids, lipids, phospholipids, and proteins. This interaction may lower CPC's biological activity, affecting its clinical efficacy. ${ }^{28}$ Unlike CPC, all four essential oils are nonionic (i.e. uncharged). An additional benefit of essential oils is that, because of their nonionic state, they do not adversely interact with positively or negatively charged ions found in dentifrices and other oral hygiene products. ${ }^{29}$

The need for effective antiplaque/antigingivitis products to be used as adjuncts to mechanical oral hygiene procedures is evident from both populationbased studies and from clinical anecdotal experience indicating a high prevalence of gingivitis. ${ }^{1}$ It is important that consumers comply with the recommended dosage regimen in order for these products to have maximum impact.

\section{Conclusion}

An in vivo gingivitis model has demonstrated the superior efficacy of an essential oil-containing mouthrinse compared to a $0.07 \%$ CPC mouthrinse in reducing supragingival plaque and gingivitis. These results should provide the dental professional with a basis for recommending daily use of EOs mouthrinses to his or her patients.

2. Lamster IB, Alfano MC, Seiger MC, Gordon JM. The effect of Listerine Antiseptic on reduction of existing plaque and gingivitis. Clin Prev Dent. 1983; 5(6):12-16. 
3. Gordon JM, Lamster IB, Seiger MC. Efficacy of Listerine antiseptic in inhibiting the development of plaque and gingivitis. J Clin Periodontol. 1985 Sep;12(8):697-704.

4. DePaola LG, Overholser CD, Meiller TF, Minah GE, Niehaus $\mathrm{C}$. Chemotherapeutic inhibition of supragingival dental plaque and gingivitis development. J Clin Periodontol. 1989 May;16(5):311-5.

5. Overholser CD, Meiller TF, DePaola LG, Minah GE, Niehaus C. Comparative effects of 2 chemotherapeutic mouthrinses on the development of supragingival plaque and gingivitis. J Clin Periodontol. 1990 Sep;17(8):575-9.

6. Charles CH, Sharma NC, Galustians HJ, Qaqish J, McGuire JA, Vincent JW. Comparative efficacy of an antiseptic mouthrinse and an antiplaque/antigingivitis dentifrice: a six-month clinical trial. J Am Dent Assoc. 2001 May;132(5):670-5.

7. Sharma N, Charles CH, Lynch, MC, Qaqish J, McGuire JA, Galustians JG, et al. Adjunctive benefit of an essential oilcontaining mouthrinse in reducing plaque and gingivitis in patients who brush and floss regularly. A six-month study. J Am Dent Assoc. 2004 Apr;135(4):496-504.

8. Charles CH, Bartels LL, Mostler KM, Mankodi SM. Comparative antiplaque and antigingivitis efficacies of a chlorhexidine and an essential oil mouthrinse: 6-month clinical trial. J Clin Periodontol. 2004 Oct;31(10):878-84.

9. Council of Dental Therapeutics. Council on dental therapeutics accepts Listerine. J Am Dent Assoc. 1988 Sep;117(3):5156.

10. Wu CD, Savitt ED. Evaluation of the safety and efficacy of over-the-counter oral hygiene products for the reduction and control of plaque and gingivitis. Periodontol 2000. 2002;28:91-105.

11. U.S. Food and Drug Administration. Oral health care drug products for over-the-counter human use; antigingivitis/antiplaque drug products; establishment of a monograph; proposed rules. Fed Regist. 2003 May 29;68(103):32241.

12. Fornell J, Sundin Y, Lindhe J. Effect of Listerine on dental plaque and gingivitis. Scand J Dent Res. 1975 Jan;83(1):18-25.

13. Mankodi S, Ross NM, Mostler K. Clinical efficacy of Listerine in inhibiting and reducing plaque and experimental gingivitis. J Clin Periodontol. 1987 May;14(5):185-8.

14. Ross NM, Mankodi SM, Mostler KL, Charles CH, Bartels LL. Effect of rinsing time on antiplaque-antigingivitis efficacy of listerine. J Clin Periodontol. 1993 Apr;20(4):279-81.

15. Amini P, Araujo MWB, Wu M-M, Charles CA, Sharma NC. Comparative antiplaque and antigingivitis efficacy of three antiseptic mouthrinses: a two week randomized clinical trial. Braz Oral Res. 2009 Jul-Sep;23(3):319-25.

16. Department of Health and Human Services, Food and Drug Administration. International conference on harmonization: good clinical practice-consolidated guideline availability. Fed Regist. 1997;62(90):25692-709.

17. Lobene RR, Weatherford T, Ross NM, Lamm R, Menaker L. A modified gingival index for use in clinical trials. Clin Prev Dent. 1986 Jan-Feb;8(1):3-6.

18. Saxton CA, van der Ouderaa FJ. The effect of a dentifrice containing zinc citrate and triclosan on developing gingivitis. J Periodont Res. 1989 Jan;24(1):75-80.

19. Turesky S, Gilmore ND, Glickman I. Reduced plaque formation by the chloromethyl analogue of Victamine C. J Periodontol. 1970 Jan;41(1):41-3.

20. Cortelli SC, Cortelli JR, Aquino DR, Costa FO. Self-performed supragingival biofilm control: qualitative analysis, scientific basis and oral-health implications. Braz Oral Res. 2010;24(Spec Iss 1):43-54.

21. Sharma NC, Araujo MW, Wu MM, Qaqish J, Charles CH. Superiority of an essential oil mouthrinse when compared with a $0.05 \%$ cetylpyridinium chloride containing mouthrinse: a six month study. Int Dent J. 2010 Jun;60(3):175-80.

22. Lisante TA, Charles C, Qaqish J, Sharma N, Junker L. Efficacy of Brush, Floss, Rinse Regimens vs. Mechanical Oral Hygiene. J Dent Res. 2011;90(Spec Iss A). Abstract, 1320.

23. Albert-Kiszely A, Pjetursson BE, Salvi GE, Witt J. Hamilton A, Persson GR, et al. Comparison on the effects of cetylpyridinium chloride with an essential oil mouthrinse on dental plaque an gingivitis - a six-month randomized controlled clinical trial. J Clin Periodontol. 2007 Aug;34(8):658-67.

24. Mankodi S, Bauroth K, Witt JJ, Bsoul S, He T, Gibb R, Dunavent $\mathrm{J}$, et al. A 6 month clinical trial to study the efficacy of a cetylpyridinium chloride mouthrinse on gingivitis and plaque. Am J Dent. 2005 Jul;18 Spec Iss:9A-14A.

25. Imrey PB, Chilton NW, Pihlstrom BL, Proskin HM, Kingman A, Listgarten MA, et al. Recommended revisions to American Dental Association guidelines for acceptance of chemotherapeutic products for gingivitis control. Report of the Task Force on Design and Analysis in Dental and Oral Research to the Council on Therapeutics of the American Dental Association. J Periodontal Res. 1994 Jul;29(4):299-304.

26. Pan PC, Harper S, Ricci-Nittel D, Lux R, Shi W. In-vitro evidence for efficacy of antimicrobial mouthrinses. J Dent Res. 2010; 38(S2):S16-20.

27. Ciancio S. Essential oils in oral health management: a review. J Clin Periodontol. 2003;30(Suppl 5):1-24.

28. DePaola LG, Eshenaur-Spolarich A. Safety and efficacy of antimicrobial mouthrinses in clinical practice. J Dent Hyg. 2007;81(5):13-25.

29. Fine DH. Mouthrinses as adjuncts for plaque and gingivitis management: a status report for the American Journal of Dentistry. Am J Dent. 1988 Dec;1(6):259-63. 